\title{
Fibromialgia: perspectivas de um campo problemático
}

Luis Eduardo Ponciano Aragon ${ }^{1}$

ARAGON, L.E.P. Fibromyalgia: perspectives of a problematic field. Interface - Comunic., Saude, Educ., v.14, n.32, p.155-69, jan./mar. 2010.

This paper related to studies on the contemporary processes of subjectivation and becoming ill, through an affirmative and non-reductionist approach towards fibromyalgia. A method named affirmation of the problematic field was formulated. This sought to resist dialectic approaches and denial of signs and symptoms, in order to pick up the procedurality of the set of affections and the production of signs today, using psychoanalytical, philosophical and clinical tools. Indiscernibility of boundaries, multiplication of surfaces and alienation of the participating rhythms of the vital processes of individuation arose as results from the study. An approach taking the body question as a field for political, ethical and clinical incidence was therefore proposed.

Keywords: Fibromyalgia. Problematic field. Subjectivation processes. Psychoanalysis. Body.
Este trabalho está ligado a pesquisas a respeito de processos de subjetivação e adoecimento contemporâneos, pela abordagem afirmativa e não reducionista da fibromialgia. Formula-se uma metodologia chamada de afirmação do campo problemático, a qual procura resistir à abordagem dialética e à negativação dos sinais e sintomas, para captar a processualidade do jogo de afetos e da produção de signos de hoje, fazendo uso de instrumental psicanalítico, filosófico e clínico. A indiscernibilidade dos limites, a multiplicação de superfícies e a alienação dos ritmos participantes dos processos vitais de individuação surgem como resultados da pesquisa e propõe-se abordar um corpo-questão como território de incidência política, ética e clínica.

Palavras-chave: Fibromialgia. Campo problemático. Processos de subjetivação. Psicanálise. Corpo.

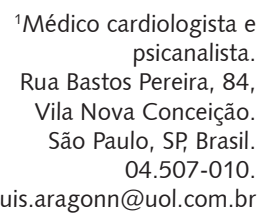

luis.aragonn@uol.com.br 


\section{Introdução}

Podemos conceber a fibromialgia [FM] como a expressão atual de sofrimentos contemporâneos, resultado de uma transformação do tecido social, implicando seus regimes de signos, sua lógica clínica, sua forma de sofrer e lidar com este sofrer.

A FM enquanto uma enfermidade que comporta dores difusas pelo corpo associadas à dor muscular em pontos específicos, faz-se acompanhar de uma série de comorbidades, como: fadiga, depressão, distúrbios do sono. Estas últimas, não sendo específicas, também podem assumir a dominância hierárquica enquanto nome do sofrer, dependendo de uma alquimia de intensidades que resiste a uma abordagem cartesiana. Esboça-se uma constelação patológica e nosográfica com limites imprecisos sugerindo a necessidade de uma aproximação singular do sofrer.

\section{Método}

\section{Paradoxo e positivação}

Parece-me fundamental buscar - na pesquisa e na clínica - uma forma de aproximação com a própria movência dos modos do sofrer, suas variações de apresentação, de tratamento e alienação.

Neste trabalho pretendo desenvolver uma metodologia que se destina a resistir a dois dos mais fortes processos do pensar, e que acompanham majoritariamente a abordagem da $F M$, a saber: o raciocínio dialético e a negativação dos sintomas.

Por raciocínio dialético ${ }^{2}$ penso na forma reducionista de apreender um processo dinâmico de produção de nomes, de modos de viver os afetos no corpo, de engendramento de gestualidades, de comportamentos, de plasticidade corporal, de abordagem técnica... Aqui, ao contrário, procurarei trabalhar com a ideia de uma concomitância paradoxal da produção/produto, buscando tocar no plano processual, o qual tem seu dinamismo maltratado quando apreendido apenas como fotografia representativa, isto é, quando fixado como sujeito ou objeto, isto ou aquilo, bom ou ruim. Veja-se que todo um esforço da comunidade de cuidadores se detém neste território dialético, quando se abre a discussão da existência ou não da doença, do fato de ela ser somática ou psíquica, ou ainda se ela é resultado de uma questão social ou individual. Seguirei por um caminho de desmonte, crítica ou proliferação de planos para resistir ao pensamento dicotômico e apaziguado.

Já por negativação dos sintomas, quero dizer da forma de alienar a positividade do processo do adoecer enquanto normatividade, ou seja, enquanto invenção de normas de um ser, vivo e ativo no mundo que o envolve, atravessa, implica ${ }^{3}$. Abordar as dores, o sono não restaurador, a depressão, como expressões de um mal a ser eliminado, é desconhecer a inteligência do vivo e da vida ${ }^{4}$, a qual encontra, a todo momento, nas protorritmicidades do mundo supraindividual (Aragon, 2007), caminhos inéditos para lidar com as exigências e encontros aos quais está submetida. Ainda além, esta forma do pensar - por negativação do engendramento processual do vivo - muitas vezes é desdobrada, para o social, enquanto déficit da provisão ambiental, ou, para o indivíduo, enquanto portador de um problema genético (Buskila, Sarzi-Puttini, 2006), de maus costumes alimentares e físicos ou de diminuição da capacidade de elaboração psíquica e simbólica. Esta busca por "culpados" ou causas específicas responsáveis pelo adoecer dificulta - quando não impede - observar a produção dinâmica, contínua e recíproca do indivíduo e do meio, bem como das formas do sofrer.

\author{
2 Dialética será tratada \\ aqui como forma de \\ pensamento baseado \\ na contradição ou \\ oposição dos termos, \\ comportando os três \\ momentos sucessivos \\ desenvolvidos por \\ Hegel: tese, antítese e \\ síntese.
}


${ }^{5}$ Acontecimento não como evento banal, mas como aquilo que "faz época", que marca o tempo, adquirindo certa eternidade, mesmo em se tratando de uma experiência cotidiana. Não é "o que acontece (acidente), ele é no que acontece o puro expresso que nos dá sinal e nos espera" (Deleuze, 2000, p.152).

6 "Patologia implica pathos, sentimento direto e concreto de sofrimento e impotência, sentimento de vida contrariada" (Canguilhem, 2000, p.106).

\section{Afirmação do campo problemático}

Nosso procedimento será chamado de afirmação do campo problemático.

Problemático, para nós, terá um estatuto muito específico, não se alinhando à concepção clássica de imperfeição do raciocínio. Por problemático entendemos o modo como os acontecimentos ${ }^{5}$ se dão (Deleuze, 2000) por meio dos encontros. O estatuto do problemático é aquele que não se restringe ao estado de coisas, aos corpos extensivos, às formas individuadas, convidando a uma transcendência da percepção e da sensação. Aspectos formais dos encontros (como eu e você, determinado objeto ou qualidade sensível) convivem com um transcender de suas formas atuais, que se exprime no limite do porvir, por meio dos modos singulares de expressão. Há sempre uma violência, um estranhamento, uma fissura ou algo que resiste à harmonização, um sofrer da vida, que revela sua presença e força, paradoxalmente, por intermédio da precariedade da estabilidade do visível, do dado, do concebido. Assim, nos distanciaremos dos métodos que se destinam ao equilíbrio, à estabilidade, à reprodutibilidade.

Se nos restringimos aos aspectos dados - como os pontos dolorosos de um corpo, as estatísticas de prevalência de uma constante na população, o nome como identidade geral extensiva a muitos indivíduos -, perdemos, de certa maneira, o vivo do sofrer, aquilo que prolifera sentidos díspares para cada ser. Os verbos no infinitivo são aqueles que mais nos guiam na direção de apreender a produção de sentidos dos acontecimentos, para além da determinação exaustiva de elementos dados. Por exemplo, descrever e delimitar a dor, sua localização, o número de pontos acometidos e a intensidade (como medida pelo dolorímetro), não dá conta de produzir os sentidos que tem um doer. Dizer que a dor é produto de inflamação ou de um delírio também não é suficiente. Portanto, procurarei ir além de uma aproximação quantitativa, e, mesmo, de uma abordagem qualitativa. O doer não é uma quantidade de fatores que, acumulados, transporiam um limiar para produzi-lo, bem como não se resume à dor, e não pode ser estendido por abstração para pessoas diferentes em situações diversas. O que chamo de problemático é justamente a multidão de elementos em presença, atuais e virtuais, tecidos em um sentido, em um "doer-questão". Esta multidão determina a radical singularidade de um acontecimento, resistindo ao processo de equivalência, o qual apagaria o modo único de se apresentar aquela dor, de se experienciar aquele adoecer. Estes modos abrem o problemático para várias linhas de sentido que atravessam questões como: qual o local onde se está? Qual o momento da vida? Quais as situações em que a dor é sentida irremediavelmente como doença? O que a alivia? Quais reações produz no entorno? Quais transformações no agir e no pensar se produzem? Mais do que linhas que fogem por todos os lados, elas fazem fugir a reificação dogmática do diagnóstico e do tratamento.

No território da clínica lidamos com demandas do sofrer. Demandas radicalmente singulares, pois cada um vive a dor, o luto, o desconforto ou o desespero de maneira diferente, e aquilo que pode ser sentido como patologia ${ }^{6}$ para um, não o é, necessariamente, para outro. Desde que nos coloquemos frente ao encontro enquanto produção de acontecimento, somos instados a implicar, em nossa ética e nosso procedimento clínico, aquilo que está aquém e além dos nomes possíveis de doenças, das formas corporais, gestuais ou subjetivas existentes, das estatísticas e teorias concebidas a priori. Somos convocados a ultrapassar o dado, em direção ao que produz sentidos e que pode forjar novos acontecimentos, variando a expressão da dor para um território mais 
alegre $^{7}$. Se concebermos o modo problemático dos acontecimentos enquanto modos do sofrer, a ação se dará por apontamentos e marcações do que rompe a trama do estabelecido na produção de sentidos. Vamos insistir. Por que esta dor? Por que agora? Por que desta forma? Por que esta terapêutica? Estes são os passaportes para, como nos propõe Orlandi, proceder a "operações de um sub/ sentir, de um entre/sentir, de um intra/sentir, extra/sentir, trans/sentir etc., e não, simplesmente, de um re/sentir" (Orlandi, 2003, p.93). Estas "variações ardilosas" são necessárias, já que estamos tratando da exploração de um mundo real, palpável, mas que não se reduz aos dados dos sentidos e nem se deixa capturar por instrumentos tecnológicos ${ }^{8}$.

De maneira nenhuma recusamos os avanços da ciência, o conjunto de dados e as descrições qualitativas produzidas na aproximação científica da FM. Ao contrário, fazemos uso destes, mas os concebemos como questões, como partes de uma problemática maior, querendo dizer com isto que cada fator já é em si uma multidão, e que a unidade em acontecimento não ocorre pela somatória de cada um, ou mesmo pela produção de outros, mas pela intensidade singular, pela forma metaestável e complexa do jogo de fatores atuais e virtuais, pelos sentidos efêmeros e vitais da contemporaneidade daquela expressão.

\section{O problema da FM - encontrando/inventando um campo}

A expressão paradoxal acima indica que nosso objeto de pesquisa não é uma objetividade (dada de antemão no mundo, esperando apenas ser descoberta ou melhor estudada), mas também não é uma abstração subjetiva. Com inspiração winnicottiana, e fiéis ao nosso procedimento, buscaremos uma apercepção ${ }^{9}$ da FM, intuindo e forjando caminhos do pensar, sem recusar a materialidade do que já foi produzido e elaborado até aqui pela ciência.

\section{Afirmação da indiscernibilidade dos limites}

Sim, a FM, bem como outras doenças que têm sido chamadas de somatomorfes (como a fadiga crônica e a síndrome do intestino irritável), causa problema.

O fato da FM verdadeiramente criar problema (diagnóstico, terapêutico e classificatório) já justifica nossa metodologia - que busca ultrapassar o problema empírico - sendo considerada por nós como uma singularidade existencial. Desta maneira, tiramos da aproximação negativa o fato mesmo de esta doença não se encaixar com facilidade em explicações causais, em limites categóricos, em respostas terapêuticas e, mesmo, em cortes demográficos rígidos.

\section{Existir ou não, eis uma questão}

Todos sabem que há grande polêmica em torno da existência ou não da FM, ou da pertinência em categorizá-la enquanto doença. O próprio comitê multicêntrico, que desenvolveu os critérios diagnósticos (Wolfe et al., 1990) utilizados até hoje, percebeu que havia uma circularidade entre a formação de critérios e os diagnósticos feitos. Cada serviço formava seus próprios critérios para formular o diagnóstico, e estes confirmavam aqueles, os quais eram diferentes para cada grupo de pesquisadores, sendo que apenas por meio do nome "fibromialgia" estabelecia-se uma associação com os dados de outros clínicos e pesquisadores. Como era de se esperar, esta comunhão denotativa escondia um mundo esquizofrênico, no qual cada um forjava sua própria
${ }^{7}$ Pensaremos na alegria, com Espinosa, enquanto aumento de potência: "Aquilo que dispõe o corpo humano de tal maneira que possa ser afetado de diversos modos ou que o torna apto a afetar os corpos externos de um número maior de modos, é útil ao homem; e é-lhe tanto mais útil quanto o corpo se torna por essa coisa, mais apto a ser afetado de mais maneiras ou a afetar os outros corpos; e, pelo contrário, é-Ihe prejudicial aquilo que torna o corpo menos apto para isto" (Espinosa, 1979, p.250).

\footnotetext{
${ }^{8} \mathrm{~A}$ filosofia positivista é tributária de invenções como a luneta de

Galileu ou o microscópio de Leeuwenhoeck, forjando a ideia de que nossos sentidos são insuficientes para a apreensão adequada do real, mas que estes mesmos sentidos, instrumentalizados, seriam capazes de "esgotar o real", de pôr a descoberto algo que só está oculto ou distorcido por nossa limitação perceptiva, e que por fim permitiria subordinar a percepção ao conceito (Muricy, 1988, p.481).
}

\footnotetext{
${ }^{9}$ No sentido que tem para Winnicott (1975) ao trabalhar a noção de espaço potencial, ou seja, aquilo que está entre o objetivamente percebido e o subjetivamente concebido.
} 
${ }^{10}$ Em fevereiro de 2008 o Food and Drug Administration (órgão regulador e fiscalizador do mercado farmacêutico americano) aprovou a primeira droga para a FM (Lyrica ${ }^{\circledR}$ - Pfizer). No entanto, os especialistas já sabem que o efeito deste medicamento para aliviar as dores é muito pobre, bem como o efeito de analgésicos, antiinflamatórios, opióides ou corticóides. A única melhora algo significativa para estas "dores fibromusculares" são os antidepressivos! (vide comentário do Dr. Knoplich disponível em <http://www1.folha uol.com.br/folha/ciencia/ ult306u371072.shtml> Acesso em: 02 fev. 2009

11 Utilizarei o termo "ser" acompanhando a especificidade que o mesmo tem na obra de

Winnicott, no sentido

de diferenciá-lo do ego

e mesmo do indivíduo, desde que para este autor, nas relações objetais primitivas, nem um nem outro constituem o centro do que poderia ser chamado de ser. Cito Winnicott:

"[...] a unidade não é o indivíduo, mas sim uma estrutura ambienteindivíduo. O centro de gravidade do ser não tem sua origem no indivíduo. Sua origem repousa na estrutura como um todo"

(Winicott apud Abram, 2000, p.240), isto é, num complexo sistema metaestável, como diria Simondon.

${ }^{12} \mathrm{O}$ autor nota que em uma pesquisa realizada com a população canadense Amish, de

hábitos muito diversos daqueles comuns no mundo ocidental, a prevalência da FM ao se utilizar o critério dos pontos dolorosos, foi muito grande. No entanto quase não se fala, neste trabalho, sobre as pessoas que tinham os "pontos dolorosos" e menos ainda o que significavam estas dores para elas. realidade e todos conversavam entre si como se falassem da mesma coisa. $\mathrm{Na}$ avaliação, pelo comitê, destes critérios diagnósticos, inúmeros elementos foram percebidos como não específicos e rejeitados enquanto determinantes para a classificação. Ao final, apenas a dor musculoesquelética generalizada, associada aos chamados "tender points", mostrou especificidade e sensibilidade discriminatórias.

Percebe-se o esforço em colocar limites, romper a comunicação esquizofrênica, criar uma unidade de percepção e de abordagem, forjar um nome que recolha, em sua materialidade, a agitação subterrânea do adoecer. Sim, é interessante que os pesquisadores e clínicos possam partilhar seus achados e suas ideias, e isto é possibilitado por algum grau de generalização. Também é importante que a dor da coluna, ou de um tumor no pulmão, possa ser diferenciada daquela da FM, e isto é possibilitado inclusive por classificações, além do saber e experiência que o profissional tem acerca de cada uma destas patologias. No entanto, há algo que não se restringe a um esmiuçar nosológico e que se impõe hoje por meio da FM, insistindo no convite a uma nova perspectiva de pesquisa e de clínica, que a tome como questão irredutível da processualidade do viver.

Delimitar, médica e juridicamente, a FM como doença tem permitido a alguns advogados conseguirem para seus clientes a proteção da seguridade social; também permite que fundos financeiros para pesquisa e centros de tratamento sejam constituídos; mas também permite a apropriação da plasticidade corporal e do sofrer pelo sistema capitalista contemporâneo, na forma de medicamentos ${ }^{10}$, terapias as mais diversas, e profissionais especializados, que nem sempre colaboram para uma compreensão global da complexidade singular e atual deste adoecer, proporcionando, muitas vezes, uma aproximação fragmentária, paternalista, e mesmo aditiva do ser ${ }^{11}$. Há toda uma política de forças envolvida na produção da superfície do que seria a FM.

Um dos principais autores dos critérios diagnósticos, o Dr. Wolfe, publicou em 2003 um interessante editorial intitulado "Parem de usar os critérios do Colégio Americano de Reumatologia na clínica" (Wolfe, 2003, p.1671-2). Nesse comunicado Wolfe coloca em questão os critérios, dizendo que eles se concentram em perspectivas físicas, deixando de lado o que diz dever ser um "diagnóstico social e político". Os pontos dolorosos e a dor difusa - enquanto elementos diagnósticos - se baseiam na mera intensidade quantitativa dos sintomas, e não em uma constelação que englobaria uma multiplicidade de fatores $^{12}$. O autor ainda constata que existe um território comum entre o que se poderia diagnosticar como FM e a artrite reumatóide, e mais, que dependendo da pressão que se faz nos pontos (ou do quanto se acredita neles - sugestão de Wolfe), o diagnóstico pode variar bastante. Por fim ele, como nós, não recusa a existência da doença pedindo, no entanto, que os reumatologistas "restabeleçam o sentido ao mundo, [...] escutem e entendam o sofrimento e os sintomas dos pacientes: tentem ajudar" (Wolfe, 2003, p.1671-2).

\section{A FM não/é psicológica}

Outro extenso campo de contenda, no que tange à $F M$, é a indiscriminação acerca de ela ser uma doença somática, psicológica, psicossomática ou psicossocial.

Apesar de o diagnóstico ter surgido no campo da reumatologia, a psiquiatria passou a se interessar progressivamente por esta doença. Na medida em que os diagnósticos, baseados em aspectos eminentemente físicos, não se faziam acompanhar de explicações causais anatômicas ou fisiológicas claras, as hipóteses de síndrome funcional, somatomorfe, de somatização ou, simplesmente, de 
"problema psicológico", passaram a ganhar terreno ${ }^{13}$. Interessa-nos aqui apenas garantir, à própria dificuldade de delimitação, um estatuto positivo. Dependendo da composição dos grupos de pesquisa, com mais ou menos profissionais "psi", reumatologistas, infectologistas, entre outros, muda-se o enfoque da doença. Em alguns casos, insiste-se nas origens genéticas, infecciosas, inflamatórias ou nutricionais, em outros, nos aspectos sociais, comportamentais e familiares. Parece que a FM "se diz" de muitas formas, contemplando o interesse de inúmeros pesquisadores, mas trai a todos, na insistência em resistir ao anseio daqueles que buscam o conforto das causalidades. Estamos em outros tempos, e a FM, em companhia de suas "parceiras", "fadiga crônica", "síndrome do intestino irritável", "déficit de atenção e hiperatividade", entre outras, exige outra abordagem, uma que implique o desconforto (e a agonia) das ciências e dos pacientes.

Mesmo nas abordagens psicossomáticas encontramos, com frequência, ações que se destinam a alienar o sofrer (talvez, sobretudo, do clínico-pesquisador) por meio de teorias que negativam o sintoma. As perspectivas clássicas acabam por buscar uma fonte do problema, a qual, no mais das vezes, é referida a algum "defeito" do indivíduo. Termos consagrados revelam esta perspectiva, como: a "alexitimia", referindo-se a baixa capacidade de elaboração e expressão das emoções; o "pensamento operatório", como característica de doentes com pouca capacidade de introspecção; ou, ainda, o "déficit de simbolização", com ascendência psicanalítica, pressupondo um conflito inconsciente ou uma pressão pulsional, que não puderam ser simbolizados, aparecendo como descarga no corpo. Mesmo a psicossomática contemporânea - a qual procura sair da clássica dicotomia corpo/ mente, por intermédio da sustentação da multiplicidade de fatores envolvidos com o adoecer e da complexidade de sua interação - ainda concebe as doenças como lesões orgânicas, objetivamente identificadas, tendo como importante fator de risco, etiologia desencadeante ou elemento de manutenção, algum componente psicossocial (Tófoli, 2004). Ela cria uma dialética que minimiza aquela do corpo/ mente em prol de outra, corpo/psicossocial. A partir daí, investiga-se o entorno, para a determinação de fatores que possam estar causando um estresse psicológico. Certamente o aumento da complexidade de análise e a atenção a fatores sociais e culturais são bem-vindos, mas ainda aqui não saímos nem da abordagem dialética, nem da negativação da expressão. Nossa aposta procedimental valora as observações que identificam as possíveis fontes de estresse trabalhista, nutricional, familiar, e todo o esforço para a redução destes elementos e do sofrer é desejável; mas, não compartilhamos da ideia hegemônica de que apenas um refinamento e aprofundamento na delimitação destes fatores deem conta do que consideramos como um verdadeiro convite, impresso com as tintas do sofrer vivo e normativo do ser, para uma mudança de lógica, de clínica, de ética e de política.

Neste terreno, tanto os clínicos como os pacientes incorrem na mesma oposição. Para estes últimos, estrategicamente, importa afastar-se da alcunha "doença psicológica", já que esta é o início da trilha que vai levar a uma desvalorização dos sintomas e sofrimentos. Multiplicam-se os sites de associações de pacientes com FM que colocam em letras garrafais a posição-mandamento "a FM não é psicológica". Como a maior parte dos cuidadores, no cotidiano do tratamento de doenças com expressão corporal, não tem formação psicológica, dizer que elas são devido ao estresse, ou que são resultado de problemas emocionais, é uma maneira de minimizar o impacto da agonia. Encaminhar para a saúde mental parece não corresponder, nem de longe, à expectativa dos doentes que sabem ser uma dor que envolve o corpo, e que sentem o cerco da culpa se fechar sobre si mesmos ao serem tidos como loucos, histéricos (com conotação pejorativa), incapazes de tolerar a pressão da vida ou ainda fingidores e preguiçosos.
${ }^{13}$ Para o

acompanhamento histórico destes termos e das polêmicas que os acompanharam e acompanham, sugiro ao leitor a introdução da tese de doutoramento de Tófoli (2004). 
Penso que esta é uma falsa questão, e que o foco deveria ser deslocado. O próprio existir desta doença faz pensar que o corpo está em outro lugar, e não naquele onde estamos habituados a procurá-lo. A questão, hoje, distribui elementos problemáticos que se localizam nas superfícies e nos processos: o trabalho progressivamente imaterial; a comunicação cada vez mais intensa e com modulação espaciotemporal enorme; o lazer, a produção e o consumo com divisões cada vez mais apagadas; a administração do tempo cada vez mais desesperadora; o acesso disseminado à violência; a ameaça continuada de exclusão. Coincidentemente, ou não, é na superfície que vem se instalar a patologia. Pele, músculo, intestino, mas também superfícies mais sutis como o tempo de atenção, o umbral sono/vigília, a fadiga/disposição, o pânico/a vida irrefletida.

O corpo-questão confronta o ser, que não pode ser apreendido apenas enquanto corpo/mente/ socius. Não que consideremos corpo e mente como a mesma coisa, há sim o soma, a extensão, como há a subjetividade, as ideias, a imaginação, o coletivo. Mas, rigorosamente pensando, esses aspectos são imersões que constituem o ser tomado por relações complexas num campo problemático, reciprocamente, convocando, insistindo, reagindo e produzindo transformações uns nos outros. A questão se dá de tal forma que todo o ser do encontro-mundo, "em vias de", é exigido, e é todo o ser que forja a expressão de suas dores e sofreres, de suas alegrias e potência, de maneira diferente a cada época-questão. O caminho para uma aproximação com o corpo-questão é a singularização do sofrer por meio de um perguntar: por que esta angústia? Por que esta forma se "in-formou" aqui e agora? O que esta dor repõe ao mundo enquanto problema?

Este corpo-questão não tem pudores em estender-se para territórios demográficos ou terapêuticos.

A FM classicamente tem atingido mulheres pobres, mas nem sempre (White, Thompson, 2003). Parece que, na América Latina, a incidência em homens é maior do que no restante do mundo, e a proporção de pacientes pobres não tão clara (Tofóli, 2004). Estas constatações insistem em perguntas e convidam o pesquisador a se lançar aos encontros, deixando-se afetar pelo campo problemático que cada doença-acontecimento instaura. Será que as mulheres pobres estão mais expostas a um registro de sobrevivência? Será que têm de suster um corpo que trabalha, cuida dos filhos, sustenta o jovem marido desempregado, e quer ter para si e sua família os impossíveis mundos que chegam até ela pela televisão? Ou estão "à margem do sistema", enquanto donas de casa sem perspectiva de ação que as singularize? Será que os homens na América Latina estão sofrendo como as mulheres pobres de outras partes do mundo? Até que ponto as condições de estresse social estão envolvidas com esta patologia? Mulheres mais abastadas manifestam menos sintomas físicos por terem mais acesso a drogas e psicoterapias?

Levantar estas questões, formular hipóteses e sair a campo procurando respostas é legítimo e importante, mas para nós este é um segundo momento, forjado pela exposição ao sofrer e ao afeto que se dá com o corpo-questão que exige movimentos, pesquisas e ações, mas se furta, todo o tempo, às respostas dogmáticas.

\section{A modulação do limite psicofisiológico}

Outra entrada instigante é a terapêutica. Os tratamentos medicamentosos que mais têm surtido efeito para a FM são, mais do que os analgésicos ou anti-inflamatórios, os antidepressivos e, com menor impacto, os que interferem na qualidade do sono. É surpreendente o fato de que, também aqui, a ação se dá nos limites/superfícies. São drogas que agem no território de interação entre a neuroendocrinologia e as emoções. Em situações ancestrais de luta ou fuga, constituíram-se regiões cerebrais como o hipotálamo e substâncias neuro-humorais como a adrenalina ou a serotonina, envolvidas na regulação dos ritmos corporais, mas também nas reações ao meio. Toda uma sutil dinâmica molecular promove alterações afetivas, o que se comprova facilmente com a administração de antidepressivos ou neurolépticos. Mas o inverso também é verdadeiro. Sabemos que a mudança frequente de fuso horário em viajantes, ou da exposição à luz daqueles que trabalham em turnos não regulares, provoca uma série de alterações na bioquímica corporal; situações de medo ou tensão constantes, associadas à impossibilidade de ação para a transformação do meio, produzem inúmeros efeitos, como hipertensão arterial, alteração de peso, diminuição da imunidade (Laborit, 1983). E é justamente nesta superfície que tem se observado a maior efetividade dos tratamentos, não só da 
FM, mas do pânico, da fadiga crônica, da hiperatividade e mesmo da dor crônica. Muitas vezes são as reações mais primitivas da complexa interface corpo/mente que são ativadas, como: taquicardia, falta de ar, tremor, palidez, suor frio, dor.

Por que os antidepressivos são os mais efetivos? Seria apenas uma questão de moda, uma que substituiu os ansiolíticos? Seriam demandas do próprio mercado, veiculadas por propaganda? Haveria uma impossibilidade de ação mutativa que impediria a afirmação da individualidade dos indivíduos? Estaria ocorrendo um descuido ou, mesmo, um ataque às regularidades temporais próprias implicadas na saúde?

\section{A multiplicação das superfícies}

A necessidade de captura da processualidade do vivo, e de controle do contingente, está fortemente relacionada com a ação de nomear, repartir, classificar. Ela é uma produção de objetos, de superfícies de contato, e nos indica outra singularidade existencial a gravitar na órbita da FM: a multiplicação de superfícies. Percebemos, hoje, um movimento nosográfico compulsivo, o que se pode perceber facilmente por meio do aumento no número de entidades a cada nova edição do Manual Estatístico e Diagnóstico de Doenças Mentais. Vivemos, hoje, em um mundo repleto de síndromes e transtornos: hiperatividade, pernas inquietas, distimia, pânico. Alguns profissionais da saúde têm tido uma abordagem crítica a este respeito, apesar de claramente minoritária, veja-se o artigo: "O que está nos deixando doentes é uma epidemia de diagnósticos" (Welch, Schwartz, Woloshin, 2007). Os autores chamam a atenção para o fato de que a associação da tecnologia com a redução progressiva dos limiares para a caracterização de doenças, e a capitalização financeira ("mais diagnósticos significa mais dinheiro"), têm sido fatores envolvidos em uma lógica, tanto sutil quanto poderosa, que leva a população a conceber-se como doente. Constata-se que, aplicando-se os critérios diagnósticos atuais, cerca de quarenta por cento da população americana estaria doente; a maior parte dos demais poderia ser considerada como portadora de uma "pré-doença" ou estando "em risco". Diagnósticos precoces são de grande valia, mas sua forma epidêmica pode trazer inúmeros problemas, como os efeitos adversos do tratamento e a medicalização da infância. A constatação de Illich de que "quanto maior a oferta de 'saúde', mais as pessoas respondem que têm problemas, necessidades e doenças, exigindo garantias contra os riscos" (Illich, 1999), aparentemente paradoxal, vai se afirmando como uma produção, e mesmo necessidade do sistema.

Levar a sério a compulsão pela demarcação, a violência da experiência com o sofrimento e a dor, a angústia de sustentar o não saber, é considerar o medo. Caso o medo da dupla frente ao desconhecido, ao processo do adoecer, ao descontrole ou ao temor do enlouquecimento seja muito grande, é possível que uma identificação tranquilizadora - como FM - venha a nascer prematuramente.

Está aberto o caminho para a abordagem multiprofissional. E esta abordagem está em ressonância, e mesmo continuidade, com a lógica/necessidade de multiplicação de superfícies.

Em boa parte das vezes, a multidisciplinaridade se estabelece como uma política do encaminhamento, do abandono ou do desapego. Para "lavar as mãos" ou com a melhor das intenções, se restabelece a esquizofrenia. A peregrinação pelos especialistas não colabora para uma apreensão geral do "mundo ambiente" 14 do paciente (compartilhado em muitos de seus elementos pelo próprio clínico, como o trabalho em excesso ou a má alimentação), e pode alienar a possibilidade do acolhimento do processo daquele sofrer.

\footnotetext{
${ }^{14}$ Mundo ambiente como aquele que está aquém ou além das formas sujeito e objeto. Que os inclui, atravessa e conforma. Um termo que procura resistir ao que, no "meio ambiente", é já separado a priori.
} 


\section{Fibromialgia em contraface: a demonização da "zona de conforto"}

\section{A distância da "zona de conforto"}

Introduzo outra estratégia para a afirmação do campo problemático. Por estar em contato, enquanto clínico, tanto com pessoas com as "doenças contemporâneas", como com pessoas do assim chamado "mundo corporativo" (com ou sem a manifestação destas doenças), faço uso da expressão "zona de conforto" como um ponto de ressonância, para trazer elementos de um mesmo mundo, mas distribuídos por tempos e espaços diferentes.

Popularizou-se, no mundo empresarial e financeiro, a ideia de que estar na "zona de conforto" é um atestado de incompetência e caducidade. Estar nesta zona significa estar perdendo o bonde da história; é poder ser visto aos olhos de colegas e superiores como um acomodado, preguiçoso e, o que é pior, sem ambição ou "empreendedorismo". Uma fala possível seria: "estava indisposta e não fui trabalhar ontem, mas não pense que eu estou na minha zona de conforto!" Ou ainda: "quando compramos uma empresa, os profissionais empregados normalmente estão fazendo um bom trabalho, mas nós mudamos a diretoria e tiramos todo mundo da zona de conforto!" Autores de falas como estas não podem imaginar que eu possa não compartilhar da ideia que têm acerca do conforto, isto pela maneira tão sutil e arraigada com que esta acepção pejorativa vingou. Em um sistema que valoriza o crescimento contínuo e o controle sobre o imprevisto, quem não está incluído em uma peregrinação de atividades (como a educação continuada ou os workshops), buscando "aprimorar o currículo" ou em auto-observação constante (sendo o "gerente de si mesmo"), é habitualmente visto com maus olhos. Ser visto assim, nas entrevistas para assumir algum emprego, nas avaliações periódicas ou mesmo na filigrana do convívio cotidiano, pode significar perda de oportunidades, de ascensão, de dinheiro e de trabalho. Não crescer continuamente pode representar estar fora do jogo e ter dificuldade de sobrevivência, o que é uma possibilidade bem concreta para boa parte da população.

Interessa-nos em especial, neste contraponto, chamar a atenção para a questão do ritmo. O sistema tem capitalizado a disposição e a competitividade de jovens que se dispõem a trabalhar muitas horas por dia, inclusive aos fins de semana, tolerar muita pressão, e corresponder à expectativa de crescimento para além do humano. São jovens que adoecem menos de FM, estando mais tecidos

${ }^{15} \mathrm{~A}$ idade média de pacientes com FM é de 49 anos para mulheres e 39 anos para homens (White et

al., 1999), enquanto o pânico aparece predominantemente

na terceira década de vida, segundo o "Practice Guideline for the Treatment of Patients With Panic Disorder" (Work Group on Panic Disorders, 1998) nas malhas do pânico ${ }^{15}$. Aqui nos concentraremos apenas na ideia de que esta força jovem e altamente selecionada impõe, em cascata, um ritmo acelerado de trabalho, pressão e ameaça, para um número enorme de pessoas, o que se traduz pela expressão-mandamento "sair da zona de conforto". Aqui também se deve sustentar o campo problemático e afetivo, não se apressando em culpar ingenuamente os jovens, ou as empresas, por exemplo.

\section{A importância do "holding" e do engendramento de ritmos}

Seguindo pelo território do ritmo, podemos dizer que o ritmo não é feito apenas de presenças, mas de presenças e ausências ou continuidades e pausas. Será que os momentos de tristeza elaborativa, de recolhimento e introspecção, ficarão restritos aos momentos de desemprego e de doença? Se assim o for, a FM, através daquilo que na dor é incontornável, mais uma vez conquista um lugar afirmativo. 
Vamos nos deter nos primórdios do enlace entre o soma e os afetos, para entender que é, neste limite, nesta superfície de engendramento mútuo, que se encontra um caminho profícuo para a aproximação da FM. O psicanalista e pediatra Donald Winnicott chamou a atenção para a importância da formação do ritmo nos primeiros momentos do bebê com sua mãe. Neste período a separação mãe/bebê é apenas uma abstração, e a subjetividade vai sendo tecida junto com o desenvolvimento do corpo. É importante, para que o bebê integre experiências aparentemente separadas, como uma luz aumentando, um cheiro de leite e uma fome torturante, que se estabeleça com a mãe um ritmo próprio, uma regularidade confiável, uma musicalidade de base, única. Só desta forma, criando ritmos emergentes no encontro dos seus com os de sua mãe, é que poderá em algum momento sentir-se um, sentir-se separado de sua mãe e dos outros, e ainda sentir que todas aquelas sensações e emoções referem-se àquele mesmo e único corpo, o seu ("conluio psicossomático"). Este processo compõe em parte o que o autor chamou de "manejo", "suporte" ou "holding", no qual o cuidador dedica-se às necessidades físico-psíquicas do bebê (Davis, Wallbridge, 1982), quando a fisiologia e a psicologia ainda não se diferenciaram. Dificuldades neste processo de integração produzem "agonias primitivas" (Winnicott, 1994, p. 72), como a de estar despedaçado, de sofrer uma queda sem fim ou de perder o senso de realidade. São mobilizadas reações corporais primitivas e o corpo pode ser sentido como separado da experiência subjetiva, chamada pelo autor de despersonalização.

Poder dispor, neste ponto, a informação de que os pacientes com FM costumam referir-se ao corpo como um estorvo, um obstáculo ou um "isso" (Söderberg et al., 2002), dá uma dimensão outra a algo que não deve ser visto apenas como um capricho de linguagem. Provavelmente estes pacientes vivem algo da desapropriação dos ritmos próprios, o que produz uma profunda agonia e algum grau de despersonalização, a qual, mais uma vez, deve ser entendida de forma positiva (perspectiva que já se encontra em Winnicott), como a saúde possível, o ritmo possível que tece, na dor, a singularidade do existir.

\section{A "desmaternagem" e a esquizoalgia}

Assim, podemos pensar que vivemos em um momento histórico, cultural, tecnológico e capitalista, no qual boa parte do povo (de qualquer classe social ou escolaridade) sofre um processo de "desmaternagem", por meio de uma expropriação insidiosa e insistente da condição de criar ritmos próprios. Os regimes de signos, por sua disseminação maciça, e a demanda do sistema com seu caráter imperativo e ameaçador (mas sedutor também), impõem necessidades comuns, projetos similares, formas clichê do viver, ou apenas uma miríade de encontros não afetivos, e não propiciam individuações singulares ${ }^{16}$, com participação original.

Inspirados em Winnicott concebemos que, para a saúde, é muito importante poder constituir um território híbrido entre a percepção do mundo "como ele é", e a certeza de que este mundo pode aceitar um colorido pessoal. Nos processos vitais e normativos que favorecem estas individuações, importa que se possa marcar o mundo com seus próprios tons, nem que isto se faça - sofrida e tragicamente - por meio da doença ou da violência. Neste sentido penso poder falar de um movimento psicotizante (por expropriação

\footnotetext{
${ }^{16}$ Apoiamos-nos em Deleuze para pensar as singularidades como aquelas que "não se confundem, [...] nem com a personalidade daquele que se exprime em um discurso, nem com a individualidade de um estado de coisas designado por uma proposição, nem com a generalidade ou a universalidade de um conceito significado pela figura ou a curva. A singularidade faz parte de uma outra dimensão, diferente das dimensões de designação, da manifestação ou da significação.

A singularidade é essencialmente pré-individual, nãopessoal, aconceitual. Ela é completamente indiferente ao individual e ao coletivo, ao pessoal e ao impessoal, ao particular e ao geral - e às suas oposições. Ela é neutra. Em compensação, não é ordinária: o ponto singular se opõe ao ordinário" (Deleuze, 2000, p.55)
} 
17 “Todo sofrer deve chamar um agir, mas um agir que não impeça o sofrer; as patologias do vivente reclamam uma medicina, mas uma medicina que respeite as patologias como forma de vida" (Stiegler 2001, p.124).

${ }^{18}$ Deleuze, ao se perguntar quais forças estão em jogo no homem contemporâneo, sugere não serem mais aquelas relacionadas a "elevação ao infinito, nem a finitude, mas um finito ilimitado, convocando assim toda a situação de força em que um número

finito de componentes oferece uma diversidade praticamente ilimitada de combinações" (2004, p.140). Não se encontra a unidade na forma infinita de Deus da idade clássica, nem na finita do homem do modernismo, mas na combinação ilimitada de elementos

e forças no homem ou, como sugere aquele autor, no super-homem nietzschiano. dos processos de individuação) e perverso (por sedução para o consumo de uma "vida invejável", e a alienação da expressão singular do desejo) do sistema lógico-capitalista atual. Esta aproximação relativiza a perspectiva que concebe doenças como a FM, o resultado de uma personalidade com estrutura psicótica ou com déficit de simbolização apenas exposta a fatores estressantes. Todos estão submetidos a esta moção que in(ex)cita enquanto aliena e fragmenta.

Illich propõe o termo esquizoalgia para referir-se à dor surgida da expropriação do sofrimento, dor que "escapa à escala humana" (Illich, 1975, p.141), traduzindo a impossibilidade de apreender a realidade íntima do viver, o que gera uma dor crônica e sem sentido. Seguindo o desmantelamento sutil e insidioso da integração rítmica dos processos perceptivos e afetivos primevos, a doença passa a ser o refúgio para uma unidade teratológica possível, um aglomerado que não se entende e... dói. Dor que integra uma experiência subjetiva e corporal no próprio nonsense de sua existência.

Não há qualquer complacência com o fato de o paciente sentir dor e sofrer. A clínica deve estar sempre voltada para a redução da dor física e a transformação do sofrimento, em favor de uma vida mais alegre e plena. Apenas não acreditamos que isto possa ser possível sem a problematização do adoecer e a produção de sentidos singulares deste processo, o que permitirá intervenções próprias para transformá-lo ${ }^{17}$.

Estaríamos em um mundo que, por fomentar a uniformização perceptiva e afetiva, impõe uma forma perversa do viver, na qual as pessoas, no momento em que canalizam seu desejo para marcar o mundo com suas questões vitais e singulares, são conduzidas à vala comum dos desejos e encontros clichê? A doença e a violência seriam passaportes sofridos, mas legítimos, para fazer valer algo de si neste mundo? Seriam estas o resultado de certa inteligência do viver?

\section{O corpo-questão na contemporaneidade}

Tomaremos apenas duas perspectivas deste corpo, a de ter seus limites paradoxalmente apagados e proliferantes. Sua superfície não para de se dobrar e desdobrar, sendo que o indivíduo tem dificuldade em encontrar uma unidade na forma de uma pessoa ou, mesmo, de um número, tem dificuldade para conquistar um ritmo, passa a ser dividual.

Este corpo é tomado por fragmentos que não remetem mais a um todo, como a tentativa de se capturar o vivo através da decifração do genoma humano ${ }^{18}$. O doente esquartejado por especialistas já não dá conta da complexidade do ser-superfície-proliferante-e-dividual. É a partir da contemporaneidade deste sofrer, que coloca em questão os próprios limites eu/outro, somático/psíquico, normal/patológico, vivo/morto, que surge a condição de aproximação com o corpo retalhado, multiplicado, desintegrado e capturado. Acompanhando Deleuze, temos hoje uma "nova medicina" "no "regime dos hospitais", "sem médico nem doente", que resgata doentes potenciais e sujeitos a risco, que de modo algum demonstra um progresso em direção à individuação, como se diz, mas substitui o corpo individual ou numérico pela cifra de uma matéria "dividual" a ser controlada" (Deleuze, 1992, p.225). Criam-se então demandas ou públicos preocupados com o colesterol, a pressão alta ou a possibilidade de ter um bebê anormal, sendo oferecidos medicamentos, técnicas de ginástica, 
dietas e exames, para consumo ${ }^{19}$. A "matéria dividual" não é nem mesmo o indivíduo reduzido a partes, pois esta "des-matéria" refere-se mais ao tempo de permanência da atenção/investimento do espectador/consumidor, para além das divisões em classes sociais, intelectuais etc. (Lazzarato, 2002). Ressalte-se que os pesquisadores têm observado distúrbios da atenção e da memória em pacientes com fibromialgia (Glass, 2006). A contemporaneidade da FM parece fazer uso da imaterialidade do jogo de forças e poder, para interferir na produção do limite doença/saúde.

Aponta-se para um processo ainda mais sutil, que vem se compor com o plano dos "seres dividuais". Percebe-se o surgimento, para além da sedução da atenção, da formação de clientelas e o gerenciamento de medos e riscos impessoais, de uma necessidade de modulação de aspectos do ser: humor, atenção, vigília, relaxamento, alegria. Um corpo que não se resume a ser vivido através da desestabilização, incitação, antecipação e controle, mas que se abre para variações infinitas. A "alegria antidepressiva", a euforia das raves, o desempenho sexual dos pênis turbinados de jovens inseguros. Drogas, as mais diversas, mas também programas de televisão, roteiro de compras, esportes, são apreendidos como formas de modular o corpo e a subjetividade, agindo "de dentro" na própria interface dos mecanismos fisiológicos, neuroendócrinos e nos órgãos dos sentidos. O corpo é excitado, exaurido, dopado, estimulado, anestesiado. Em parte, observa-se uma tentativa de minimizar o sofrer por meio dos inescapáveis caminhos modulatórios e capitalizados de hoje. Por outra parte, há uma progressiva exigência estética e opressiva. A necessidade de estar sempre bem, alegre, disposto, mais produtivo, vai se expandindo pelo social, atingindo gradativamente as crianças $^{20}$. Para um psicanalista estas questões são concretas e graves, pois não raro as pessoas se surpreendem desesperadas por sentiremse deprimidas (mesmo havendo motivo para tal) ou por perceberem, atônitas, que um dia estão alegres e, em outro, nem tanto, o que pode parecer caricato, mas traduz uma vivência de profunda angústia e sofrimento. O que revela uma visceral sensação de desconfiança quanto às próprias percepções e intuições, ou seja, uma sensação de enlouquecimento na apresentação do sofrer, o que demanda a urgência de uma confirmação "de fora" de que aquilo é "normal". O sofrer dos "afetos existenciais" (Guattari, 1987, p. 50) envolvidos com o luto, o adoecer, a morte, o nascimento, as conquistas, são vividos como delirantes e ameaçadores de uma "normalidade" que já não se acessa mais naturalmente, necessitando de um fiador.

Qual clínica trataria das angústias - impensáveis - vividas no plano das superfícies proliferantes e em variação infinita? Qual encontro possível? Como acolher, dar sentido, sarar, as feridas desta pele? Como propiciar encontros que sejam verdadeiros acontecimentos, no sentido de produzir ritmos?

As perguntas não pedem resposta, sabemos, mas este conjunto de questõescorpo insiste.

O acontecimento que é o encontro clínico não entulhado de teorias e pressuposições pode escutar uma mulher pobre, com diagnóstico de fibromialgia, que "não deu atenção ao corpo", em seu caminho de sobrevivência através de uma infância violenta ${ }^{21}$ e de um trabalho excessivo dividido entre a cozinha de uma escola pública, os filhos e o marido. Pode perceber esta mesma mulher fazendo o mundo parar, o campo de afetação se restringir, os familiares transformando a administração dos tempos e espaços, frente à doença incapacitante (Alves, 2005). O clínico, des-pré-ocupado em saber se a doença existe ou não, se é ou não psicológica ou ainda se é causada por este ou aquele motivo, pode dispor-se vulnerável ao encontro e, a partir daí, inventar uma clínica.
${ }^{19}$ Rabinow esclarece bem como, na atualidade, os dados da presença imediata vão cedendo lugar à necessidade de antecipação de riscos impessoais projetados no futuro, quando diz que "a prevenção moderna é antes de tudo mapeamento de riscos. O risco não é o resultado de perigos específicos colocados pela presença imediata de uma pessoa ou um grupo de pessoas, mas sim a fusão de 'fatores' impessoais que tornam um risco provável. Assim, a prevenção é a vigilância, não do indivíduo, mas sim de prováveis ocorrências de doenças, anomalias, comportamentos desviantes a serem minimizados, e de comportamentos saudáveis a serem maximizados.

Estamos aos poucos abandonando a antiga vigilância face-a-face de indivíduos e grupos já conhecidos como perigosos ou doentes, com finalidades disciplinares ou terapêuticas, e passando a projetar fatores de risco que desconstroem e reconstroem o sujeito individual ou grupal, ao antecipar possíveis loci de irrupções de perigos, através da identificação de lugares estatisticamente localizáveis em relação a normas e médias" (Rabinow, 1999, p.145). Estes "fatores impessoais" forjam não só uma "bioidentidade" que está para além dos limites individuais e grupais, como uma "biossociabilidade" (Rabinow, 1999, p.135-57). Sugiro que este processo não se restrinja à biotecnologia, mas atinja planos mais imateriais, como sociedades moduladas por "tempos de atenção dedicados a". 
${ }^{20}$ Começa-se a propor 0 "uso estético" de drogas como a Ritalina ${ }^{\circledR}$, para melhorar a atenção o desempenho escolar (à revelia do mundo da criança, que pode esta literalmente desabando!)

${ }^{21}$ A violência na infância inclusive a sexual, tem sido relacionada ao quadro de FM (Terre, Guiselli, 1997).

${ }^{22}$ Entenda-se que clínica é utilizada neste trabalho não apenas no sentido mais restrito de atendimento a pacientes, mas que a própria perspectiva problemática de concepção do artigo pretendeu ter "efeito de acontecimento" no encontro com o leitor, promovendo uma variação das formas de perceber e sentir neste campo, sendo, portanto clínica por si só.

\section{Conclusão}

Este trabalho é o resultado de um esforço para dar voz ao corpo-questão que me atravessa enquanto pesquisador, clínico e indivíduo implicado nos sofreres deste tempo.

Escolher - ou ser escolhido - pela FM, forjar um conjunto de procedimentos singulares, tentar apreender, por entre as palavras e ideias, algo do inapreensível e, no entanto, tão concreto da angústia, faz parte da aposta na força do viver que encontra, a cada momento, caminhos para seguir, mesmo que pelo adoecer. Aposta que busca retirar a FM de um território que a submete ao negativo e às abordagens dialéticas e causais.

Exploramos o que nos pareceu serem singularidades existenciais envolvidas com a questão-mundo da FM, como a indiscernibilidade dos limites, a proliferação de superfícies, e a captura pelo sistema de produção de capital. Tocamos o movimento de um processo progressivo de alienação dos ritmos participantes dos processos vitais de individuação, e o aparecimento correlativo de agonias impensáveis. Percorremos um corpo mutante que é tomado por partes, pelo fato mesmo de multiplicar sua superfície, tornando-se dividual, impessoal e genérico, encontrando, na dor e na modulação dos limites, instrumentos desesperados de ancoragem do ser singular.

Acredito que, a partir daí, é possível entrever uma clínica ${ }^{22}$ que se afirma na potência de criação de ritmos nos encontros (Aragon, 2007); uma ética que busca, em cada situação, acolher as singularidades da individuação; uma política que vê no adoecer do corpo uma forma legítima de expressão do viver, mesmo sabendo que devemos fazer todo o possível para aliviá-la.

\section{Agradecimento}

O esboço deste trabalho foi apresentado em maio de 2008 para o Grupo de Trabalho Subjetividades Contemporâneas, por ocasião do Simpósio da Associação Nacional de Pesquisa e Pós-graduação em Psicologia, coordenado por Suely Rolnik e formado por Beatriz Sancovschi, Cristina Rauter, Eduardo Passos, Elizabeth Lima, Elizabeth Pacheco, Fernanda Bruno, Flávia Liberman, João Leite Neto, Liliana da Escóssia, Luciana Caliman, Peter Pál Pelbart, Silvia Tedesco, Virgínia Kastrup e William Pereira. Agradeço a todos por suas contribuições.

\section{Referências}

ABRAM, J. A linguagem de Winnicott: dicionário das palavras e expressões utilizadas por Donald W. Winnicott. Trad. Marcelo G. da Silva. Rio de Janeiro: Revinter, 2000.

ALVES, A.S. A repercussão da dinâmica familiar na sintomatologia da fibromialgia. 2005. Dissertação (Mestrado) - Universidade São Marcos, São Paulo. 2005.

ARAGON, L.E.P. O impensável na clínica: virtualidades nos encontros clínicos. Porto Alegre: Sulina/Ed. UFRGS, 2007.

BUSKILA, D.; SARZI-PUTTINI, P. Biology and therapy of fibromyalgia; genetic aspects of fibromyalgia syndrome. Arthritis Res. Ther., v.8, n.5, p.218-22, 2006. 
CANGUILHEM, G. O normal e o patológico. Trad. Maria T.R.C. Barrocas e Luiz O.F.B. Leite. Rio de Janeiro: Forense Universitária, 2000.

DAVIS, M.; WALLBRIDGE, D. Limite e espaço: uma introdução à obra de D. W. Winnicott. Trad. Eva Nick. Rio de Janeiro: Imago, 1982.

DELEUZE, G. Foucault. Paris: Les Éditions de Minuit, 2004.

Lógica do sentido. Trad. Luiz Roberto Salinas Fortes. São Paulo: Perspectiva, 2000 34, 1992.

Conversações, 1972 - 1990. Trad. Peter Pál Pelbart. Rio de Janeiro: Editora

ESPINOSA, B. Ética. São Paulo: Abril Cultural, 1979. (Os Pensadores)

GLASS J.M. Cognitive dysfunction in fibromyalgia and chronic fatigue syndrome: new trends and future directions. Curr. Rheumatol. Rep., v.8, n.6, p.425-9, 2006.

GUATTARI, F. Ritornelles et affects existentiels. Revue Chimères, n.7, p.40-55, 1989. Disponível em: <http://www.revue-chimeres.fr/drupal_chimeres/files/07chi03.pdf>. Acesso em: 4 maio 2008.

ILLICH, I. A obsessão da saúde perfeita. Trad. Jô Amado. Le Monde Diplomatique, 12 dez, 1999. Disponível em: <http://diplo.uol.com.br/1999-12,a1609?var recherche $=\mid$ van\% 20Illich $>$. Acesso em: 4 fev. 2009

A expropriação da saúde: nêmesis da medicina. Trad. José Kosinski de Cavalcanti. Rio de Janeiro: Nova Fronteira, 1975.

LABORIT, H. La colombe assassinée. Paris: Grasset, 1983.

LAZZARATO, M. Les revolution du capitalisme. Paris: Les Empêcheurs en Rond, 2002.

MURICY, K. Os olhos do poder. In: NOVAES, A. (Org.). O olhar. São Paulo: Companhia das Letras, 1988. p.479-86.

ORLANDI, L.B.L. O indivíduo e sua implexa pré-individualidade. Cad. Subjetividade, ISBN 8527106159, p.87-96, 2003.

RABINOW, P. Antropologia da razão: ensaios de Paul Rabinow. Trad. João Guilherme Biehl. Rio de Janeiro: Relume Dumará, 1999.

SÖDERBERG, S.; LUNDMAN, B.; NORBERG, A. The meaning of fatigue and tiredness as narrated by women with fibromialgia and healthy women. J. Clin. Nurs., v.11, n.2, p.24755, 2002.

STIEGLER, B. Nietzsche et la biologie. Paris: PUF, 2001.

TERRE, L.; GUISELLI, W. A developmental perspective on family risk factors in somatization. J. Psychosom. Res., v.42, n.2, p.197-208, 1997.

TÓFOLI, L.F.F. Investigação categorial e dimensional sobre sintomas físicos e síndromes somatomorfes na população geral. 2004. Tese (Doutorado) - Faculdade de Medicina, Universidade de São Paulo, São Paulo. 2004.

WELCH, H. G.; SCHWARTZ, L.; WOLOSHIN, S. What's making us sick is an epidemic of diagnoses. New York Times, jan. 2, 2007. Disponível em: <http://query.nytimes.com/ gst/fullpage.html?res=9C01EED71630F931A35752C0A9619C8B63>. Acesso em: 21 nov. 2009.

WHITE, K.P. et al. The London fibromyalgia epidemiology study: the prevalence of fibromyalgia syndrome in London, Ontario. J. Rheumatol., v.26, n.7, p.1570-6, 1999.

WHITE, K.P.; THOMPSON, J. Fibromyalgia syndrome in an Amish community: a controlled study to determine disease and symptom prevalence. J. Rheumatol., v.30, n.8, p.183540, 2003. 
WINNICOTT, D.W. O medo do colapso (breakdow). In: WINNICOTT, C.; SHEPHERD, R.; DAVIS, M. (Orgs.). Explorações psicanalíticas: D. W. Winnicott. Trad. José Octávio de Aguiar Abreu. Porto Alegre: Artes Médicas, 1994. p.70-6.

A localização da experiência cultural. In: O brincar e a realidade. Rio de Janeiro: Imago, 1975. p.133-43.

WOLFE, F. et al. The American College of Rheumatology 1990 criteria for the classification of fibromyalgia: report of the multicenter criteria committee. Arthritis Rheum., v.33, n.2, p.160-72, 1990.

WOLFE, F. Stop using the American College of Reumatology criteria in the clinic. J. Rheumatol., v.30, n.8, p.1671-2, 2003.

WORK GROUP ON PANIC DISORDERS. American psychiatric association. Practice guideline for the treatment of patients with panic disorder. Am. J. Psychiatr., v.155, suppl.5, p.1-34, 1998.

ARAGON, L.E.P. Fibromialgia: perspectivas de un campo problemático. Interface Comunic., Saude, Educ., v.14, n.32, p.155-69, jan./mar. 2010.

Este trabajo se vincula a investigaciones sobre los procesos de subjetivación y padecimiento contemporáneos mediante un abordaje afirmativo y no reduccionista de la fibromialgia. Para ello se formula una metodología denominada afirmación del campo problemático, tendiente a resistir al abordaje dialéctico y a la negativación de las señales y los síntomas, para captar la procesualidad del juego de afectos y de la producción de signos en la actualidad, haciendo uso de instrumental psicoanalítico, filosófico y clínico. La indiscernibilidad de los límites, la multiplicación de superficies y la alienación de los ritmos participantes en los procesos vitales de individuación surgen como producto de esta investigación. Se plantea aquí abordar un cuerpo-cuestión como territorio político, ético y clínico.

Palabras clave: Fibromialgia. Campo problemático. Procesos de subjetivación. Psicoanálisis. Cuerpo. 